\section{Cureus}

Received 10/25/2015

Review began 11/03/2015

Review ended 11/18/2015

Published 12/04/2015

\section{(c) Copyright 2015}

Bhatti et al. This is an open access article distributed under the terms of the Creative Commons Attribution License CC-BY 3.0., which permits unrestricted use, distribution, and reproduction in any medium, provided the original author and source are credited.

\title{
Cross-Reactivity of Rapid Salmonella Typhi IgM Immunoassay in Dengue Fever Without Co-Existing Infection
}

\author{
Adnan Bashir Bhatti ${ }^{1}$, Farhan Ali $^{2}$, Siddique Akbar Satti ${ }^{2}$ \\ 1. Medical Director of Clinical Research, Spine Surgery, Tristate Brain and Spine Institute, United States, \\ Atlanta, USA 2. Department of Medicine, Capital Development Authority Hospital, Islamabad, Pakistan
}

$\square$ Corresponding author: Adnan Bashir Bhatti, dr.adnanbashir@gmail.com

Disclosures can be found in Additional Information at the end of the article

\section{Abstract}

Introduction:

Dengue fever is endemic in developing nations worldwide with as many as 500,000 annual cases of dengue hemorrhagic fever (DHF) and dengue shock syndrome (DSS). A prompt and accurate diagnosis early in the disease course is essential for prompt identification and treatment of severe complications of the dengue virus infection (DVI). We identified crossreactivity of a rapid IgM test for typhoid fever in patients with febrile illnesses that were determined to be due to dengue virus.

Methods:

All patients with documented DVI during a recent epidemic in Pakistan also underwent diagnostic testing for Salmonella enterica serovar Typhi. The diagnosis of DVI was made based on clinical findings and the positive results for dengue non-structural protein 1 antigen $\left(\mathrm{NS}_{\mathrm{Ag}}\right)$ and/or dengue IgM antibody (anti-D IgM) during the acute phase of febrile illness. Patients with positive test results for Salmonella typhi (S. Typhi) IgM also had their blood cultures done.

Results:

In the group of 322 patients with clinical and serological evidence of DVI, 107 also tested positive for S. Typhi IgM. Blood cultures were negative for S. Typhi bacteria in all patients. Principal disease features included fever, headache, myalgia, retro-orbital pain, and a rash accompanied by thrombocytopenia and leukopenia. Comparisons of clinical and routine laboratory findings between the S. Typhi-positive and negative groups showed no significant differences. Patients testing positive for both $\mathrm{NS}_{\mathrm{Ag}}$ and anti-D IgM were significantly more likely to test positive for S. Typhi IgM, even in the absence of typhoid fever. No routine antibiotics were used and all patients survived.

Conclusion:

One-third of a large group of patients with primary DVI also demonstrated false positive results for typhoid fever. Cross-reactivity of a rapid immunoassay for typhoid fever has not been previously reported in DVI or any other flavivirus infections. Until these findings can be further evaluated, clinicians should be cautious in interpreting $\mathrm{S}$. Typhi rapid immunoassays and have a high index of suspicion of DVI in dengue fever endemic areas.

Categories: Internal Medicine, Infectious Disease, Public Health Keywords: dengue fever, misdiagnosis, febrile fever, dengue hemorrhagic fever, dengue false positive, 


\section{Introduction}

The global incidence of dengue virus infections (DVI) has increased dramatically over the past several decades [1-4]. Current worldwide case burden estimate ranges from 20 to 100 million infections annually, including as many as 500,000 cases of dengue hemorrhagic fever (DHF) and dengue shock syndromes (DSS) [4-5]. The annual estimates of DVI-associated mortality exceed 20,000. Other potentially serious infectious organisms that have a similar worldwide endemic distribution include Salmonella typhi (S. Typhi) [6]. An accurate diagnosis of DVI is essential in order to identify, as early as possible, those patients at risk for the critical phase of the infection and possible circulatory collapse, shock, and death. It may be difficult to diagnose DVI based only on clinical criteria during the acute phase of febrile Illness. The principal symptoms are non-specific and difficult to distinguish from numerous other febrile illnesses of viral or bacterial origin [7-10]. Thus, patients with febrile illnesses often benefit from specific diagnostic laboratory studies for dengue virus and other candidate infectious organisms endemic to the region [11-12]. In the case of S. Typhi, concurrent dengue fever and typhoid fever are uncommon [11].

During a recent epidemic of dengue fever in Pakistan, febrile patients were tested for DVI by dengue-specific IgM and IgG (anti-D IgM/IgM) immunoassays usually accompanied by dengue non-structural protein 1 antigen $\left(\mathrm{NS}_{\mathrm{Ag}}\right.$ ) testing. Patients also underwent screening for $\mathrm{S}$.

Typhi infection using a rapid immunoassay for S. Typhi-specific IgM/IgG. A number of patients with confirmed DVI were noted also to have positive S. Typhi IgM results despite negative S. Typhi blood cultures. False positive results of rapid immunoassays for antibodies to S. Typhi outer membrane protein in patients with DVI have not previously been reported. Recognizing the risks of an incorrect diagnosis of typhoid fever resulting in delayed treatment of potentially life-threatening complications of DVI, we conducted a more systematic evaluation of the typhoid rapid chromatographic immunoassay in patients with DVI. The Human Ethics Committee of the Capital Development Authority (CDA) Hospital, Islamabad, Pakistan, approved this study.

\section{Materials And Methods}

\section{Patients}

Three hundred and twenty-two patients with a diagnosis of primary DVI during a recent epidemic in the Rawalpindi and Islamabad regions in Pakistan between September and December 2012 comprised this study. The medical records of these patients were examined and study data were placed into a master clinical and laboratory database. The clinical data comprised of the findings on the admission history and physical examination, including details of any prior flavivirus infections and signs and symptoms of an acute illness that included high fever and myalgia accompanied by retro-orbital pain, headaches, facial flushing, or a petechial rash. Informed patient consent was obtained at the time of treatment.

\section{Laboratory studies}

All patients had their white blood cell, platelet counts, liver transaminases (AST, ALT), alkaline phosphatase (ALP), and urinalyses test completed. Patients with suspected DVI had serum tested for dengue $\mathrm{NS}_{\mathrm{Ag}}$ (RapiGEN Biocredit, Germany) and anti-D IgM/IgM (RapiGEN

Biocredit, Germany). Both of these tests are rapid lateral flow chromatographic immunoassays [13-14].

The diagnosis of primary DVI was based on the typical clinical presentation described above 
and laboratory test results that were positive for $\mathrm{NS}_{\mathrm{Ag}}$ and/or anti-D IgM, with negative findings for anti-D IgG. Patients with anti-D IgG on initial screen were excluded from this analysis. Positive anti-D IgM results were confirmed after one week by an ELISA anti-D IgM ELISA kit (Diagnostic Automation/Cortez Diagnostics, Inc., USA). All patients with DVI also were tested for S. Typhi through IgM and IgG chromatographic immunoassay (Typhoid IgG/IgM Rapid Test, Biocan Diagnostics Inc., Canada). A blood culture was done for all patients with positive S. Typhi IgM antibody testing. For the purpose of this study, only patients who were S. Typhi IgM positive and IgG negative were considered in the results. All immunoassays were done according to manufacturer's instructions with appropriate controls.

\section{Statistical analysis}

Descriptive statistics are expressed as mean $( \pm \mathrm{SD})$ and comparisons of categorical variables used the Chi-square test or Fisher's Exact test. Continuous variables in the groups testing positive or negative for S. Typhi IgM were compared using the Student T-test. A p-value $\leqslant 0.05$ was considered significant.

\section{Results}

A total of 322 patients with DVI comprised this study. The mean age was $37.1 \pm 15.6$ years (range: 15-70), and there were 126 females (39.1\%).

Of the 322 patients, $\mathrm{NS}_{\mathrm{Ag}}$ and anti-D IgM/IgG tests were performed on 308 patients and the remaining 15 were only tested for anti-D IgM/IgG antibodies. There were positive results for $\mathrm{NS}_{\mathrm{Ag}}$ in 255/308 patients (82.7\%) and 274/322 (85\%) tested positive for anti-D IgM. None of the 322 patients tested for anti-D IgM had anti-D IgG detected. Of all 322 patients with DVI, 107 (33.2\%) tested positive for S. Typhi IgM and none of them had positive results for S. Typhi IgG antibodies. Blood cultures were performed in order to check the presence of bacterial infection and all were found to be negative. Clinical characteristics of the S. Typhi IgM-positive and negative groups are compared in Table 1 . 


\section{Cureus}

\begin{tabular}{|c|c|c|}
\hline & \multicolumn{2}{|l|}{ Rapid Typhoid IgM } \\
\hline & Positive $n=107$ & Negative $n=215$ \\
\hline Gender (m:f) & 1.7:1 & 1.5:1 \\
\hline Age (years) & $38 \pm 17$ & $36 \pm 15$ \\
\hline Temperature (F) & $102.4 \pm 1.6$ & $102.3 \pm 1.6$ \\
\hline \multicolumn{3}{|l|}{ Blood Pressure (mm Hg) } \\
\hline Systolic (Blood Pressure) & $110.1 \pm 9.4$ & $110.8 \pm 7.1$ \\
\hline Diastolic (Blood Pressure) & $67.5 \pm 9.0$ & $68.3 \pm 8.7$ \\
\hline Respiratory rate (/min) & $13.6 \pm 1.4$ & $13.5 \pm 1.4$ \\
\hline Headache & $107(100 \%)$ & $215(100 \%)$ \\
\hline Fever (no. patients \%) [mean \pm SD] & 107 (100\%) [102.4 土 1.63] & $215(100 \%)[102.4 \pm 1.56]$ \\
\hline Myalgia & 107 (100\%) & $215(100 \%)$ \\
\hline Retro-orbital pain & $99(93 \%)$ & $193(89 \%)$ \\
\hline Facial flushing & $85(80.2 \%)$ & $164(76 \%)$ \\
\hline Petechial rash & $39(37 \%)$ & $72(33 \%)$ \\
\hline Conjunctival congestion & $23(22 \%)$ & $44(20 \%)$ \\
\hline Nasopharyngeal bleeding & $15(14 \%)$ & $30(14 \%)$ \\
\hline
\end{tabular}

TABLE 1: Principal initial clinical characteristics of 322 patients with primary dengue virus infection (DVI).

Results of laboratory studies according to S. typhi groups are summarized in Table 2. 


\section{Cureus}

\begin{tabular}{|c|c|c|c|}
\hline & \multirow[b]{2}{*}{ Normal Values (Range) } & \multicolumn{2}{|l|}{ Rapid Typhoid IgM } \\
\hline & & Positive $n=107$ & Negative $n=215$ \\
\hline Total WBC count $(/ \mu \mathrm{L})^{*}\left[/ 10^{9} / \mathrm{L}\right]$ & $\begin{array}{l}\left(4.00-11.0 \times 10^{3} / \mu L\right)[4.00-11.0 \times \\
\left.10^{9} / L\right]\end{array}$ & $\begin{array}{l}2,700 \pm 880(2.7 \pm \\
0.88)\end{array}$ & $\begin{array}{l}2,240 \pm 1,120(2.24 \pm \\
1.12)\end{array}$ \\
\hline Platelet Count $\left(\times 10^{3 / \mu L}\right)^{*}\left[\times 10^{9} / \mathrm{L}\right]$ & $\begin{array}{l}\left(150-450 \times 10^{3} / \mu \mathrm{L}\right)[150-450 \times \\
\left.10^{9} / \mathrm{L}\right]\end{array}$ & $\begin{array}{l}65.1 \pm 46(65.1 \pm \\
46)\end{array}$ & $60.4 \pm 42(60.4 \pm 42)$ \\
\hline $\begin{array}{l}\text { Alanine aminotransferase }(\mathrm{U} / \mathrm{L})^{*} \\
{[\mu \mathrm{kat} / \mathrm{L}]}\end{array}$ & (10-40 IU/L) [0.17-0.68 $\mu \mathrm{kat} / \mathrm{L}]$ & $\begin{array}{l}81.8 \pm 22(1.37 \pm \\
0.37)\end{array}$ & $81.3 \pm 21(1.36 \pm 0.35)$ \\
\hline $\begin{array}{l}\text { Aspartate aminotransferase }(\mathrm{U} / \mathrm{L})^{*} \\
{[\mu \mathrm{kat} / \mathrm{L}]}\end{array}$ & 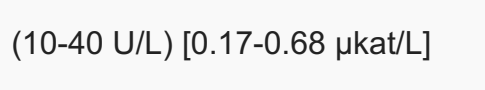 & $\begin{array}{l}89.2 \pm 23(1.49 \pm \\
0.38)\end{array}$ & $87.6 \pm 21(1.46 \pm 0.35)$ \\
\hline Alkaline phosphatase $(\mathrm{U} / \mathrm{L})^{*}[\mu \mathrm{kat} / \mathrm{L}]$ & (36-92 U/L) [0.5-1.5 $\mu \mathrm{kat} / \mathrm{L}]$ & $\begin{array}{l}408 \pm 62(6.81 \pm \\
1.04)\end{array}$ & $397 \pm 68(6.63 \pm 1.14)$ \\
\hline \multicolumn{4}{|l|}{ Dengue $\mathrm{NS1}_{\mathrm{Ag}}(\mathrm{n})$} \\
\hline Positive result & & $95(88.8)$ & $160(79.6)$ \\
\hline Negative result & & $12(11.2)$ & $41(20.4)$ \\
\hline \multicolumn{4}{|l|}{ Dengue IgM antibody } \\
\hline Positive result & & 98 (91.6) & 176 (81.9) \\
\hline Negative result & & $9(8.4)$ & $39(18.1)$ \\
\hline
\end{tabular}

\section{TABLE 2: Principal initial laboratory test results in 322 patients with primary dengue virus infection (DVI).}

*Study results are mean $\pm 1 S D$ and $(S I$ mean $\pm 1 S D)$.

Although there were no clinical or routine laboratory findings that distinguished the groups, cross-reactivity of the S. typhi IgM test was significantly associated with the presence of anti-D IgM antibodies. Those patients with positive results for both $\mathrm{NS} 1_{\mathrm{Ag}}$ and anti-D IgM were significantly more likely to have a false positive test for S. typhi IgM compared to patients testing negative for both $(\mathrm{p}<0.001)$ (Table 3). 


\section{Cureus}

\begin{tabular}{|c|c|c|c|}
\hline & $\begin{array}{l}\text { Typhoid IgM POS GROUP n } \\
\text { (\%) }\end{array}$ & $\begin{array}{l}\text { Typhoid IgM NEG GROUP n } \\
\text { (\%) }\end{array}$ & $\begin{array}{l}\text { Fisher Exact } P \\
\text { value }\end{array}$ \\
\hline${ }^{N S 1}{ }_{A g}$ Positive & $95(88.8)$ & $160(79.6)$ & \multirow{2}{*}{0.0563} \\
\hline $\mathrm{NS}_{\mathrm{Ag}}$ Negative & $12(11.2)$ & $41(20.4)$ & \\
\hline Dengue IgM Positive & 98 (91.6) & $176(81.9)$ & \multirow{2}{*}{0.0206} \\
\hline Dengue IgM Negative & $9(8.4)$ & $39(18.1)$ & \\
\hline $\begin{array}{l}\text { Both NS1 Ag and Dengue lgM } \\
\text { Positive }\end{array}$ & $100(93.5)$ & $155(77.1)$ & \multirow{2}{*}{0.0002} \\
\hline $\begin{array}{l}\text { Both NS1 Ag and Dengue IgM } \\
\text { Negative }\end{array}$ & $7(6.5)$ & $46(22.9)$ & \\
\hline
\end{tabular}

TABLE 3: Probabilities of false positive S. typhi IgM in dengue virus infection (DVI) by rapid immunoassay.

All patients were treated with paracetamol and parenteral fluids. Forty-nine patients required platelet transfusions for profound thrombocytopenia and/or bleeding. No antibiotics were administered for the false positive culture negative S. typhi tested patients.

\section{Discussion}

The diagnosis of the acute phase of DVI during the febrile phase was based on clinical presentation with confirmatory testing with dengue $\mathrm{NS} \mathrm{Ag}$ and dengue-specific IgM antibodies in most patients. During the acute phase, the combined uses of these tests provide reliable results for all dengue virus serotypes [9-15] with reported sensitivities and specificities of $89 \%$ and above [13, 16-17].

Likewise, contemporary rapid immunoassays for typhoid fever combined with blood cultures for S. Typhi have enabled the timely diagnosis of typhoid fever, particularly in developing nations [18]. To the best of our knowledge, the cross-reactivity in typhoid negative dengue fever has not been described to date.

Early in the course, symptoms of DVI are generally nonspecific, usually characterized by several days to one week of high fever and often accompanied by a headache, retro-orbital pain, malaise, myalgia, and arthralgia. At this phase of illness, it is clinically difficult to distinguish DVI with confidence from numerous other infectious illnesses, including S. Typhi. However, making an accurate diagnosis during the acute phase of the febrile illness is essential for prompt intervention since it is difficult to predict whether the patient will progress to the critical phase characterized by a rapid onset of a severe capillary leak, circulatory collapse, and hemorrhage with thrombocytopenia. These patients require hospitalization and support with meticulous fluid and, when necessary, platelet infusions.

Based on the findings in this study, patients in the febrile phase of DVI may be at risk for misdiagnosis of typhoid fever based on the cross-reactivity of a rapid immunoassay for anti-S. 
Typhi IgM antibodies. Delays in rapid diagnosis of DVI can be life-threatening. The potential impact of inaccurate diagnostic testing using relatively low cost, rapid assays is considerable since the incidence of DVI worldwide is rapidly increasing [19], particularly in developing nations, including Pakistan, where seasonal dengue epidemics are common. In many of these same regions, typhoid fever is endemic. This greatly increases the risk of misdiagnosis of DVI as typhoid.

It is highly likely that our patient sample had primary DVI and not a secondary infection since circulating dengue $\mathrm{NS}_{\mathrm{Ag}}$ was identified in almost all cases accompanied by anti-D IgM but no IgG antibodies. In a group of patients with DVI, sensitivity and a positive predictive value of 97.3\% and 100\%, respectively, was observed for NS1Ag when NS1 antigen-capture ELISA was used [13].. In other studies, the combination of NS1 Ag and anti-D IgM immunoassay testing have similar performance when combined [17]. Although IgM also may appear early in secondary infections, dengue-specific IgG usually appears early as well, as an amnestic response regardless of the infecting dengue serotype [12]. It is highly unlikely that the patients testing positive with the IgM rapid test for typhoid fever represented a group with dengue virus and S. Typhi co-infection. Although such patients have previously been reported, the patients in our study had negative blood cultures and recovered without the routine use of antibiotics.

There are several types of tests for DVI that required different levels of clinical laboratory expertise and resources. The diagnosis of DVI can be done by viral culture, molecular techniques, or immunospecific testing for the presence of the dengue antigen or anti-dengue IgM and IgG antibodies in the blood. Viral culture provides confirmatory evidence of infection but is not useful for early diagnosis. Reverse transcription polymerase chain reaction (PCR) for dengue has a high sensitivity and specificity, but such testing requires laboratory expertise and resources not available in many of the endemic areas. Test kits for DVI that do not require high levels of technical resources include $\mathrm{NS}_{\mathrm{Ag}}$ and anti-D IgM/IgG antibodies [20-21]. There are no reports of cross-reactivity of these immunoassay kits with S. Typhi. However, the common use of NS1Ag, anti-D IgM/IgG, and anti-S. Typhi IgG/IgM diagnostic kits in developing nations where typhoid fever is also common greatly increases the risk of false positive testing for typhoid fever in patients with DVI.

Our findings should be cautiously taken into account until further studies confirm this observation in other dengue virus outbreaks. However, clinicians and clinical laboratory personnel must be aware that a positive anti-S. Typhi IgM does not exclude the possibility of a DVI, nor is it sufficient to conclude that the illness is due to a co-infection.

\section{Conclusions}

We report false positive (cross-reactivity) results for S. Typhi serum IgM by rapid chromatographic immunoassay in one-third of patients during the febrile phase of DVI. Physicians should be aware of this cross-reactivity in endemic or epidemic areas of dengue virus to prevent life-threatening complications of DVI. There should be a high index of suspicion of DVI in patients who present with positive S. Typhi IgM by rapid immunoassay. Treatment focused on typhoid fever due to cross-reactivity of tests may preclude the timely diagnosis and intervention of life-threatening complications of DVI.

\section{Additional Information \\ Disclosures}

Human subjects: Consent was obtained by all participants in this study. The Ethics Committee of the Capital Development Authority (CDA) Hospital, Islamabad, Pakistan, approved this study. issued approval N/A. In Pakistan, no approval numbers are assigned to studies approved by the 
Ethics Committees of hospitals. Animal subjects: All authors have confirmed that this study did not involve animal subjects or tissue. Conflicts of interest: In compliance with the ICMJE uniform disclosure form, all authors declare the following: Payment/services info: All authors have declared that no financial support was received from any organization for the submitted work. Financial relationships: All authors have declared that they have no financial relationships at present or within the previous three years with any organizations that might have an interest in the submitted work. Other relationships: All authors have declared that there are no other relationships or activities that could appear to have influenced the submitted work.

\section{References}

1. Bhatt S, Gething PW, Brady OJ, Messina JP, Farlow AW, Moyes CL, Drake JM, Brownstein JS, Hoen AG, Sankoh O, Myers MF, George DB, Jaenisch T, Wint GR, Simmons CP, Scott TW, Farrar JJ, Hay SI: The global distribution and burden of dengue . Nature. 2013, 496:504-7. 10.1038/nature12060

2. Nathan MB, Dayal-Drager R, Guzman M, et al: Epidemiology, burden of disease and transmission. Dengue: Guidelines for Diagnosis, Treatment, Prevention and Control. Ciceri K, Tissot P (ed): WHO, France; 2009. 3-21.

3. Daumas RP, Passos SR, Oliveira RV, Nogueira RM, Georg I, Marzochi KB, Brasil P: Clinical and laboratory features that discriminate dengue from other febrile illnesses: a diagnostic accuracy study in Rio de Janeiro, Brazil. BMC Infect Dis. 2013, 13:77. 10.1186/1471-2334-13-77

4. Gubler DJ: Epidemic dengue/dengue hemorrhagic fever as a public health, social and economic problem in the 21st century. Trends Microbiol. 2002, 10:100-3. 10.1016/S0966842X(01)02288-0

5. Murray NE, Quam MB, Wilder-Smith A: Epidemology of dengue: past, present and future prospects. Clin Epidemiol. 2013, 5:299-309. 10.2147/CLEP.S34440

6. Crump JA, Luby SP,Mintz ED: The global burden of typhoid fever . Bull World Health Organ. 2004, 82:346-53.

7. Wiwanitkit V: The importance of accurate diagnosis of dengue fever . Future Virol. 2012, 7:5362. 10.2217/fvl.11.129

8. Mazumder RN, Pietroni MA, Mosabbir N, Salam MA: Typhus fever: An overlooked diagnosis. J Health Popul Nutr. 2009, 27:419-21.

9. Kaushik A, Pineda C, Kest H: Diagnosis and management of dengue fever in children. Pediatr Rev. 2010, 31:e28-35. 10.1542/pir.31-4-e28

10. Guzman MG, Halstead SB, Artsob H, Buchy P, Farrar J, Gubler DJ, Hunsperger E, Kroeger A, Margolis HS, Martínez E, Nathan MB, Pelegrino JL, Simmons C, Yoksan S, Peeling RW: Dengue: a continuing global threat . Nat Rev Microbiol. 2010, 8:S7-16. 10.1038/nrmicro2460

11. Sudjana P, Jusuf H: Concurrent dengue hemorrhagic fever and typhoid fever infection in adult: Case report. Southeast Asian J Trop Med Public Health. 1998, 29:370-72.

12. Buchy P, Peeling R: Laboratory diagnosis and diagnostic tests. Dengue: Guidelines for Diagnosis, Treatment, Prevention and Control . Ciceri K, Tissot P (ed): WHO, Geneva; 2009. 91-107.

13. Kumarasamy V, Wahab AH, Chua SK, Hassan Z, Chem YK, Mohamad M, Chua KB: Evaluation of a commercial dengue NS1 antigen-capture ELISA for laboratory diagnosis of acute dengue virus infection. J Virol Methods. 2007, 140:75-79. 10.1016/j.jviromet.2006.11.001

14. Vazquez S, Lemos G, Pupo M, et al: Diagnosis of dengue virus infection bu the visual and simple AuBioDot immunoglobulin M capture system. Clin Diagn Lab Immunol. 2003, 10:1074-1077. 10.1128/CDLI.10.6.1074-1077.2003

15. Aryati A, Trimarsanto H, Yohan B, Wardhani P, Fahri S, Sasmono RT: Performance of commercial dengue NS1 ELISA and molecular analysis of NS1 gene of dengue viruses obtained during surveillance in Indonesia. BMC Infec Dis. 2013, 13:611. 10.1186/1471-2334-13-611

16. Arya SC, Agarwal N, Parikh SC, Agarwal S: Simultaneous detection of dengue NS1 antigen, IgM plus IgG and platelet enumeration during an outbreak. Sultan Qaboos Univ Med J. 2011, 11:470-76.

17. Dussart P, Labeau B, Lagathu G, Louis P, Nunes MR, Rodrigues SG, Storck-Herrmann C, Cesaire R, Morvan J, Flamand M, Baril L: Evaluation of an enzyme immunoassay for detection 


\section{Cureus}

of NS1 antigen in human serum. Clin Vaccine Immunol. 2006, 13:1185-89.

10.1128/CVI.00229-06

18. Hatta M, Goris MG, Heerkens E, Gooskens J, Smits HL: Simple dipstick assay for the detection of Salmonella typhi-specific IgM antibodies and the evolution of the immune response in patients with typhoid fever. Am J Trop Med Hyg. 2002, 66:416-21.

19. Shepard DS, Undurraga EA, Halasa YA: Economic and disease burden of dengue in Southeast Asia. PLoS Negl Trop Dis. 2013, 7:e2055. 10.1371/journal.pntd.0002055

20. Guzman MG, Kouri G: Dengue diagnosis advances and challenges. Int J Infect Dis. 2004, 8:6980. 10.1016/j.ijid.2003.03.003

21. Kao CL, King CC, Chao DY, Wu HL, Chang GJ: Laboratory diagnosis of dengue virus infection: current and future perspectives in clinical diagnosis and public health. J Microbiol Immunol Infect. 2005, 38:5-16. 